\title{
REVIEW
}

Open Access

\section{Is objectively measured light-intensity physical activity associated with health outcomes after adjustment for moderate- to-vigorous physical activity in adults? A systematic review}

Shiho Amagasa, Masaki Machida, Noritoshi Fukushima, Hiroyuki Kikuchi, Tomoko Takamiya, Yuko Odagiri and Shigeru Inoue

\begin{abstract}
Background: An increasing number of studies have demonstrated that light-intensity physical activity (LPA) confers health benefits after adjustment for moderate-to-vigorous physical activity (MVPA). The purpose of this systematic review was to summarize existing epidemiological evidence on associations of objectively measured LPA with health outcomes in adults.

Methods: This review was conducted in accordance with the Preferred Reporting Items for Systematic Reviews and Meta-Analyses guidelines. We searched on PubMed, Web of Science, CINAL, and Cochrane Library for articles analyzing the association between objectively determined LPA and health outcomes that were published up to January 2017. Data were extracted regarding authors, publication year, country of survey, study setting, number of participants, study design, physical activity (PA) assessment (type of accelerometer and intensity), health outcomes, confounders, and results (summary measures and association). A coding system was used to summarize the results.

Results: Of the 3254 studies identified, 24 cross-sectional and 6 longitudinal studies were included in this review. Most of the studies targeted the Western population. LPA was inversely associated with all-cause mortality risk and associated favorably with some cardiometabolic risk factors including waist circumference, triglyceride levels, insulin, and presence of metabolic syndrome. Only a small amount of data were available on mental health and cognitive function.

Conclusions: LPA appears to be beneficially associated with important health outcomes after adjustment for MVPA in the adult population. Although current global PA guidelines recommend only MVPA, promoting LPA may confer additional health benefits.
\end{abstract}

Keywords: Accerelometry, Epidemiology, Public health, Lifestyle activity, Physical activity

\footnotetext{
* Correspondence: inoue@tokyo-med.ac.jp

Department of Preventive Medicine and Public Health, Tokyo Medical

University, Tokyo, Japan
}

(c) The Author(s). 2018 Open Access This article is distributed under the terms of the Creative Commons Attribution 4.0 International License (http://creativecommons.org/licenses/by/4.0/), which permits unrestricted use, distribution, and reproduction in any medium, provided you give appropriate credit to the original author(s) and the source, provide a link to the Creative Commons license, and indicate if changes were made. The Creative Commons Public Domain Dedication waiver (http://creativecommons.org/publicdomain/zero/1.0/) applies to the data made available in this article, unless otherwise stated. 


\section{Background}

It is well documented that moderate-to-vigorous physical activity (MVPA) is effective in the prevention of major non-communicable diseases including type 2 diabetes, coronary heart disease, stroke, and some types of cancer [1]. Current global physical activity (PA) guidelines recommend that adults engage in at least $150 \mathrm{~min}$ of MVPA in a week or 75 min of vigorous PA in a week in bouts of at least $10 \mathrm{~min}$ to achieve health benefits [2]. Even though LPA has great potential for increasing total PA levels (i.e., PA energy expenditure) [3, 4], the effect of light-intensity PA (LPA) has remained controversial. It has been reported that people spend a significant portion of their time in sedentary behavior (SB) and LPA and only a little time in MVPA [5-7]. According to the National Health and Nutrition Examination Survey (NHANES) data, within a day $(24 \mathrm{~h})$, adults spent an average of $7.7 \mathrm{~h}$ in SB, $7.8 \mathrm{~h}$ in LPA, $0.2 \mathrm{~h}$ in MVPA, and $8.3 \mathrm{~h}$ in sleep [6]. Thus, the clarification of the effects of LPA is crucial to promote public health.

The topic of epidemiological studies has shifted from MVPA to the health benefits of LPA, owing to the development of accelerometry techniques in epidemiological studies [8,9]. Even though several studies have confirmed the potential health benefits of self-rated LPA (e.g., housework) $[10,11]$, recalling the time spent in LPA dispersed throughout the day may be difficult compared with MVPA lasting for at least $10 \mathrm{~min}$. Objective assessment can record more detailed and accurate patterns of personal daily activity [9, 12]. Emerging evidence suggests that objectively determined LPA is associated with all-cause mortality [13], cardiometabolic biomarkers [14], and plasma glucose levels [15] after adjustment for MVPA time.

To date, there have been no comprehensive reviews published to our knowledge on whether objectively measured LPA is associated with health outcomes after adjustment for MVPA. Fuzeki et al. [16] recently reviewed the health benefits of objectively measured LPA, but they focused on only the NHANES dataset and hence generalizability of the data is limited. Moreover, most studies, including the review by Fuzeki et al. did not adjust for MVPA, which may confound the associations of LPA with health. Therefore, the aim of this present review was to systematically examine associations of objectively assessed LPA and health outcomes after adjustment for MVPA in adults.

\section{Methods}

\section{Information sources and searches}

Information searches were performed in accordance with the Preferred Reporting Items for Systematic Reviews and Meta-Analyses (PRISMA) guidelines [17]. Studies were obtained through searching the following four electronic databases: PubMed, Web of Science, CINAL, and Cochrane Library. We performed the search on February 2, 2017, using the search terms presented in Additional file 1. These search terms are created based on a previous study [18]. A hand search was also carried out to supplement the electronic database searches.

\section{Study selection}

Inclusion and exclusion criteria were determined prior to undertaking the review. We included the following observational studies: 1) those that assessed associations of objectively measured LPA with at least 1 health outcomes, 2) targeted adults, and 3) were written in English or Japanese. We included studies that analyzed the effects of various intensities of PA, provided that they also analyzed the association between LPA and the outcomes. No limitation on publication year was included.

Studies were excluded if they met the following criteria: 1) targeted only a particular populations in the medical setting (e.g., patients, survivors, or pregnant women), 2) investigated the association with physical fitness, 3) did not control for covariates, and 4) was not an original research article.

\section{Data extraction and study quality assessment}

Data extraction and study quality assessment was performed by two independent researchers (SA and MM), and differences in judgement between the two researchers were discussed until they reached a consensus. The extracted data included the following information: author(s), publication year, county of survey, population (sex and age), number of participants, study design, PA assessment (intensity, type of accelerometer, LPA cut off points, and duration of LPA), health outcomes, and results (summary measures and association).

The quality of the included studies was assessed using the Quality Assessment Tool used in a previous review [16]. Briefly, this assessment tool includes a 12-item checklist, and items were coded as 'present (1)' or 'absent/ unclear (0)'. Studies scoring 10 points and above, 9-6 points, and below 6 points were classified as high, moderate, and low quality, respectively. Because of the heterogeneity of the study designs, outcome variables, statistical analyses, and the context in which the data were collected, a meta-analysis was not applied. Therefore, a narrative synthesis of the evidence was conducted. The data synthesis included findings from the studies analyzed, such as study design, sample, accelerometer (definition of LPA), exposure, outcomes (direction), confounders, and quality assessment.

A coding system created by Sallis et al. [19] was used to summarize the association between LPA and health outcomes. The results were classified as follows: "no association (0)" if $0 \%-33 \%$ of the papers reported a 
statistically significant difference between LPA and outcomes, "indeterminate (?)" if $34 \%-59 \%$ of the papers indicated a statistically significant difference, and "favorable association (+)/unfavorable association (-)" if $60-100 \%$ of the papers showed a statistically significant favorable/ unfavorable difference. When more than four studies supported an association or no association, it was coded as "00", “++", or "--". The "??" was used if there were inconsistent findings. We used the results of the final model of multivariate analyses (fully adjusted model) if multiple models were run in one study. Studies analyzing multiple health benefits were included in each of the relevant items.

\section{Results}

\section{Search and selection}

A flow diagram of article inclusion is shown in Fig. 1. A total of 5059 potential studies were identified through electronic database searching (1848 from PubMed, 2218 from Web of Science, 845 from Cochrane Library, and 148 from CINAL). After removing duplicate records, 3254 articles remained. Of these, 3164 articles were excluded by means of title and abstract screening and 90 full text articles were assessed for eligibility. After reading the full text, 28 were concluded to meet the inclusion criteria, and two were added by further searching. As a result, 30 articles were included in this review.

\section{Study characteristics and quality assessment}

The characteristics of the studies reviewed are described in Table 1. Among the 30 eligible studies, 17 included adults ( $>18$ years) (men: 2; women: 2; and both: 13), four included older adults (men: 1; women: 0 ; and both: 3 ), and nine included both adults and older adults (men: 0 ; women: 1 ; and both: 8 ). We were unable to summarize the results by age group (i.e., adults or older adults) owing to limited data. The eligible papers were published between 2007 and February 2017, and most of them $(n=24,80 \%)$ were cross-sectional studies. Seventeen of the included studies were from the United States, and the rest were from the United Kingdom $(n=3)$, Australia $(\mathrm{n}=3)$, Canada $(n=1)$, Belgium $(n=1)$, Finland $(n=1)$, Japan $(n=1)$, Taiwan $(n=1)$, Sweden $(n=1)$, and Saudi Arabia $(n=1)$. Study samples ranged from 50 to 5562 and half of the studies $(n=15)$ had a sample of more than 1000 participants. Most of the studies were of moderate quality.

\section{Definition of light-intensity physical activity}

The majority of the studies assessed LPA using the ActiGraph accelerometer (Actigraph, LLC, FL) $(n=26,84 \%)$; however, various cut off points were ued to determine LPA including 100-1951 counts per minute (CPM) [14, 15, 20-25], 100-2019 CPM [13, 26-30], 150-2689 CPM [31], 760-2019 CPM [32], 251-1951 CРM [33, 34], 100-1040 СРM [35], 100-759 СРM [36], 200-1998

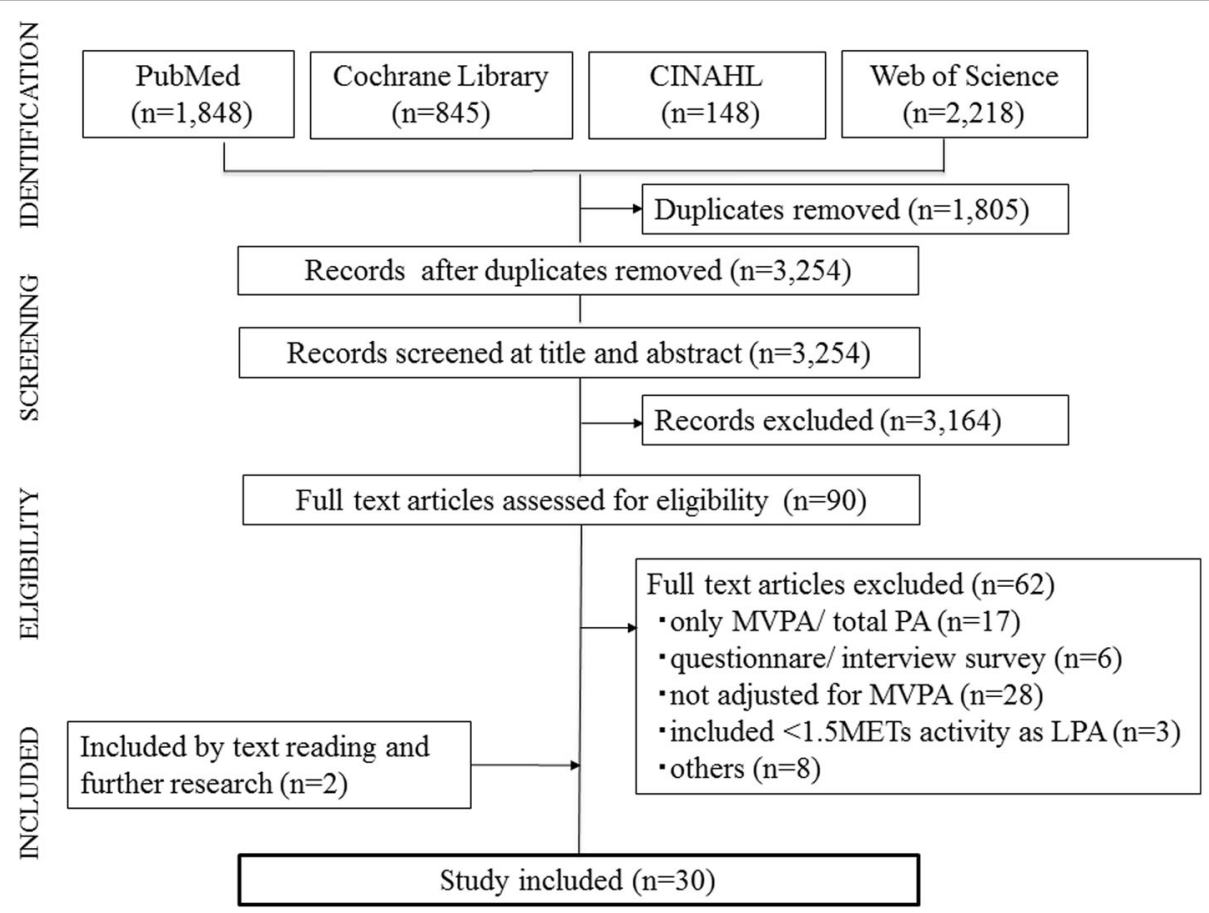

Fig. 1 Flow diagram of the inclusion of articles in this study. PA: physical activity, LPA: light-intensity physical activity, MVPA: moderate-to-vigorous physical activity 


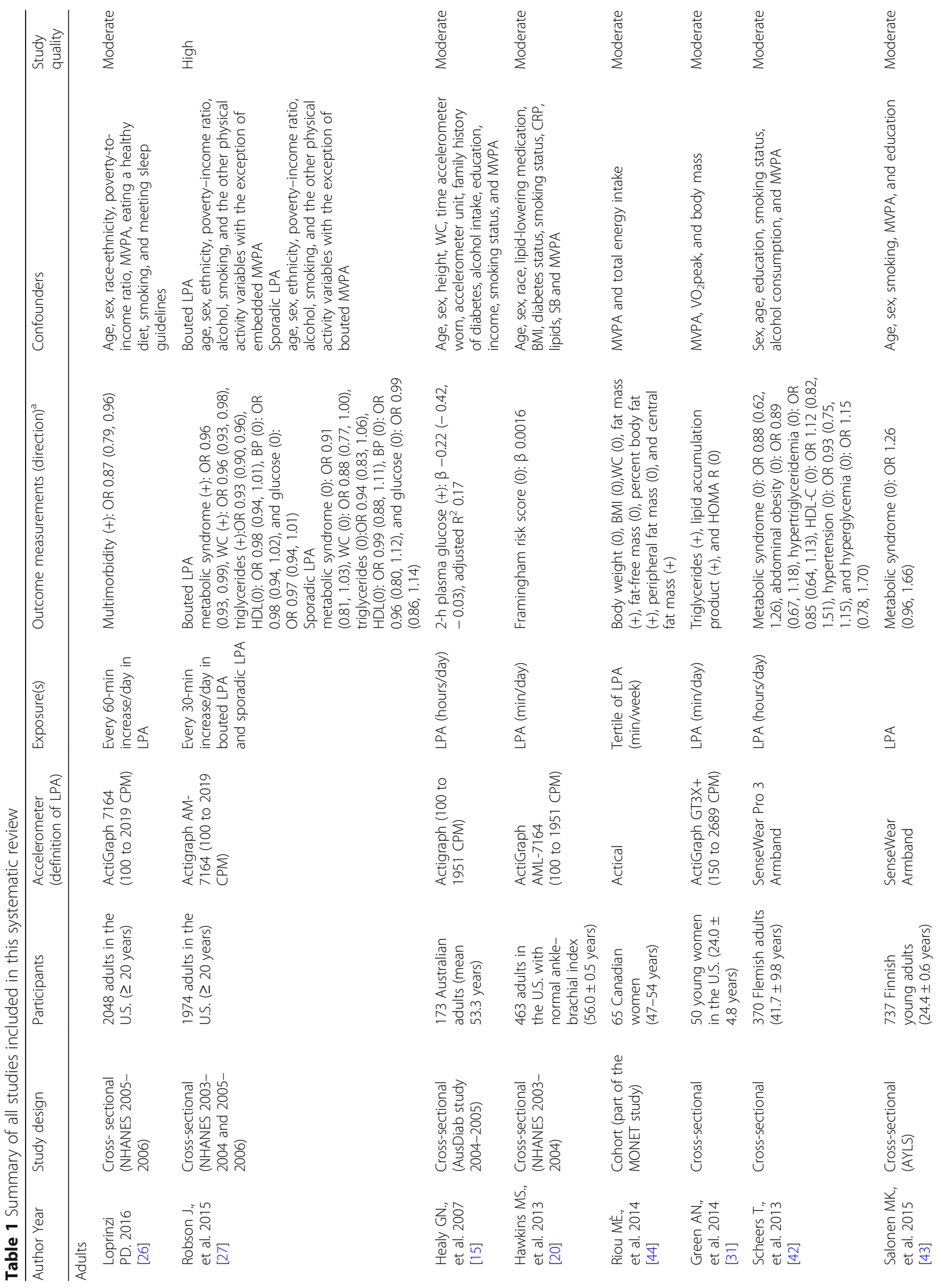




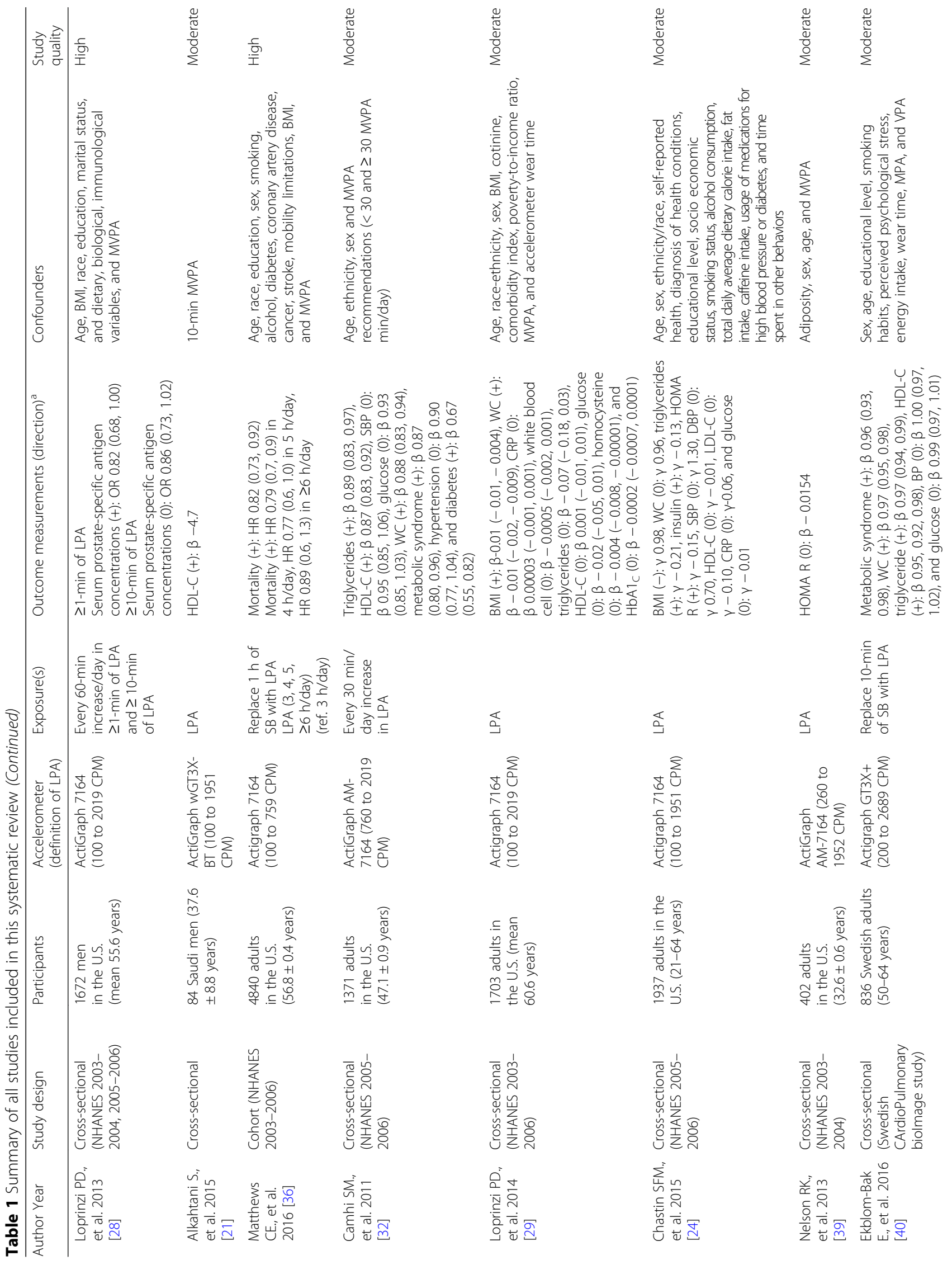




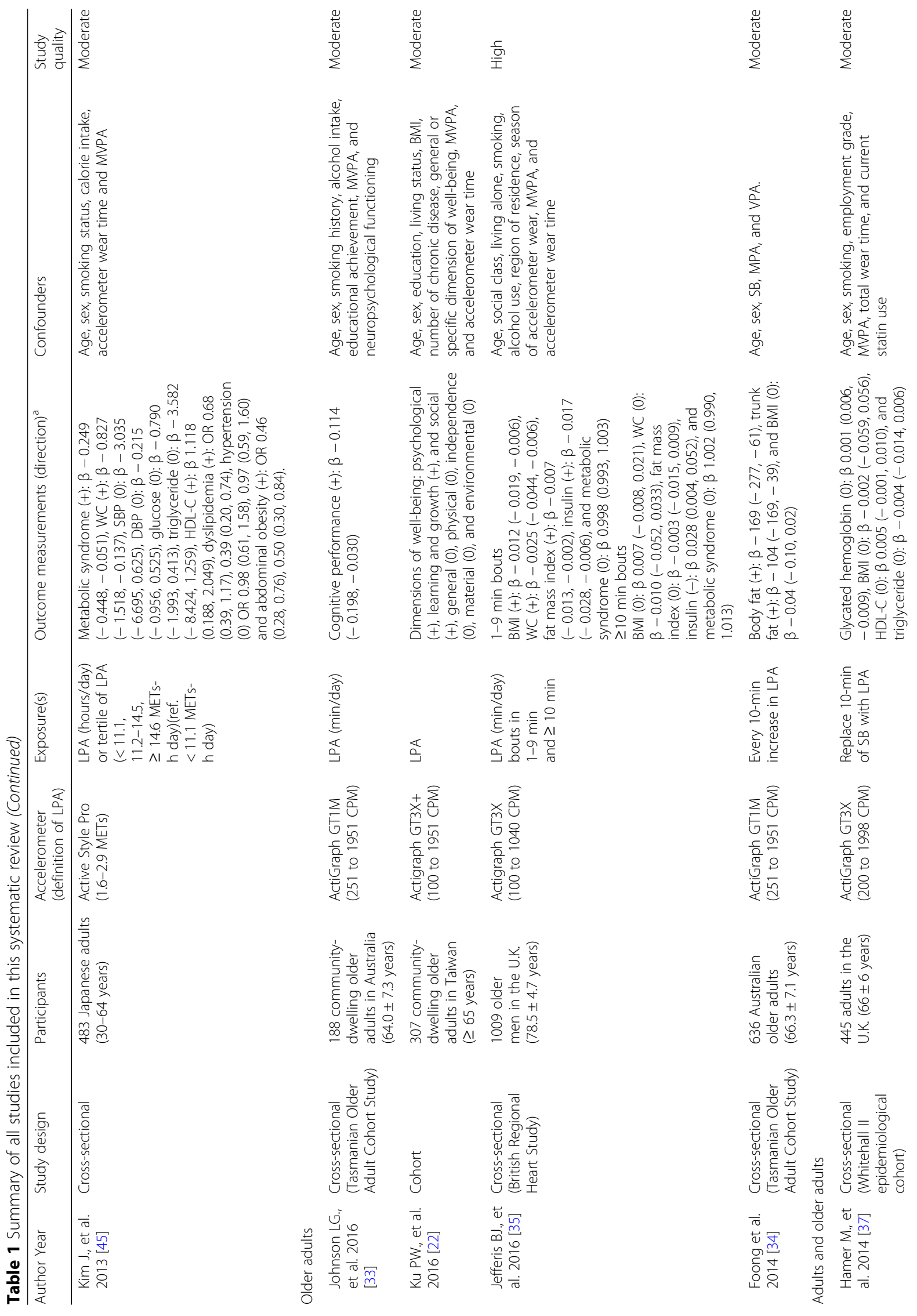




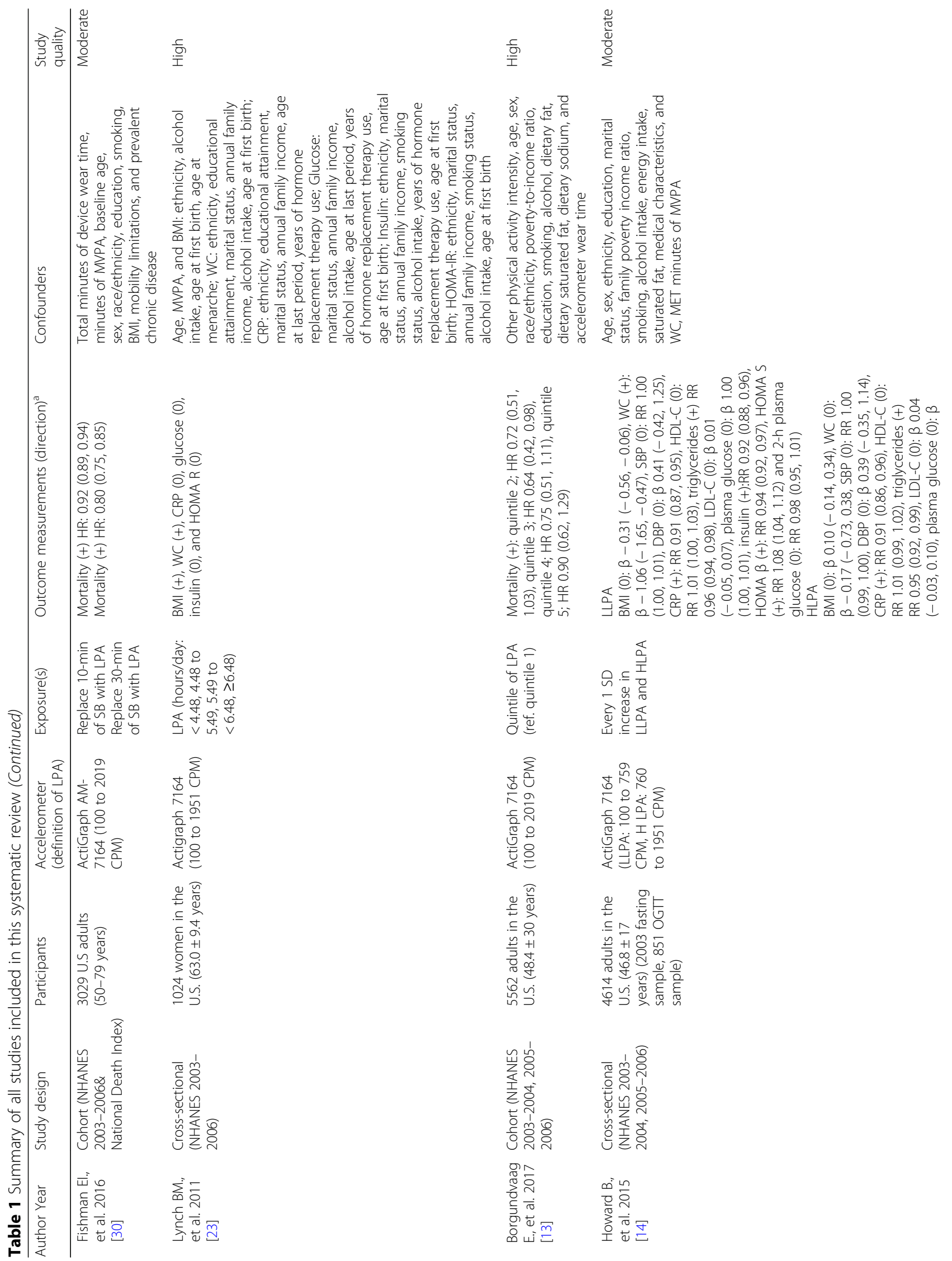




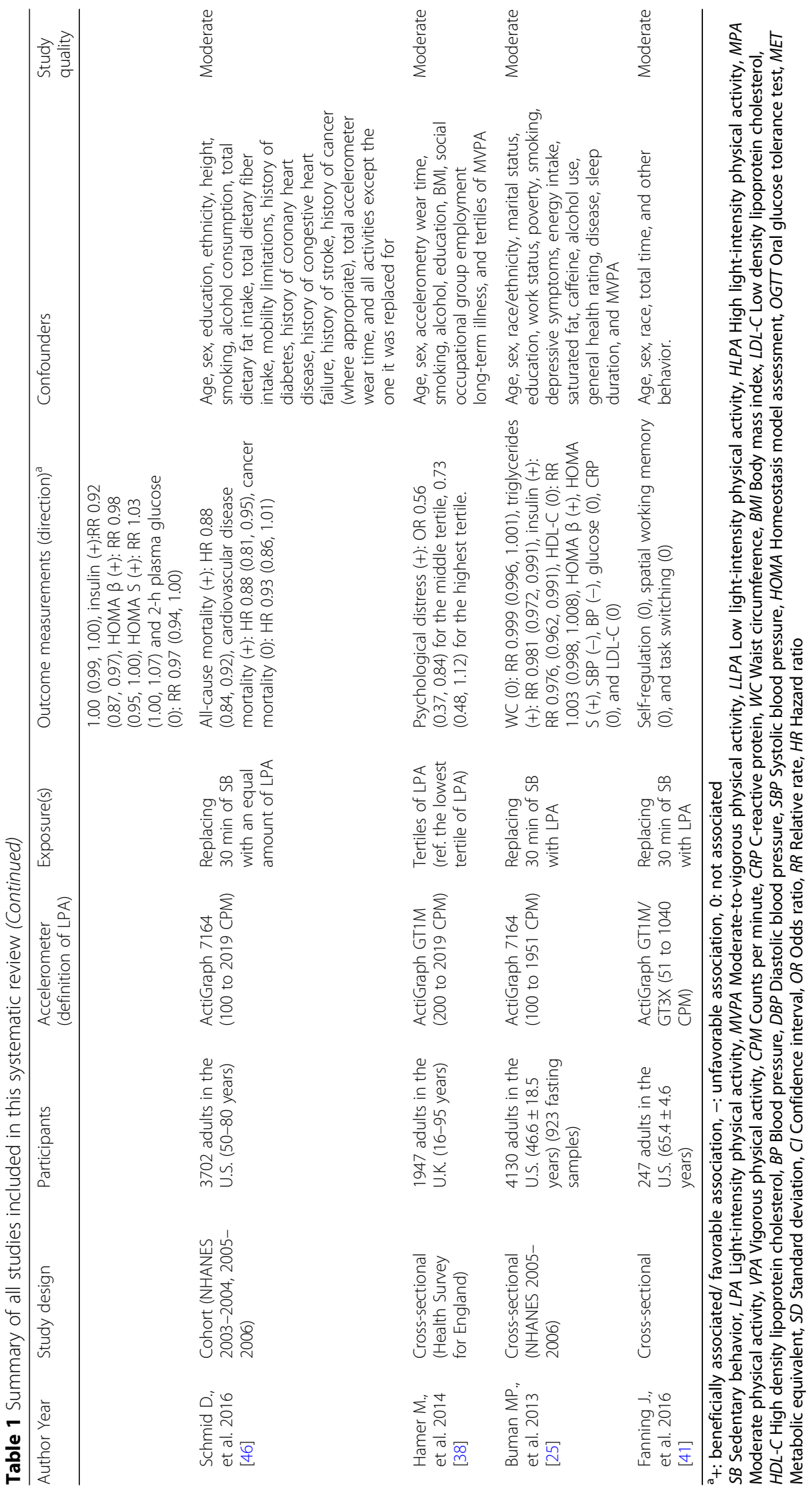


CPM [37], 200-2019 CPM [38], 260-1952 CPM [39], 200-2689 CPM [40], and 51-1040 CPM [41]. Of the remaining four observational studies, two used the SenseWear Armband (BodyMedia, Inc., PA) with $>1.5$ to <3.0 Metabolic Equivalents (METs) [42, 43], one used the Actical (Mini Mitter Co., Inc., OR) with $>1.5$ to $<3.0$ METs [44], and one used the Active style Pro (Omron Healthcare Co., Ltd., Kyoto, Japan) with 1.6-2.9 METs [45]. One study [14] categorized LPA into two types according to intensity, namely, low light-intensity physical activity (LLPA) (100-759 CPM) and high light-intensity physical activity (HLPA) (760-1951 CPM).

\section{Health outcomes}

The association between LPA and health outcomes reported in each study is presented in Table 1 , and a summary of the included studies is listed in Table 2.

\section{Cross-sectional studies}

Cardiometabolic risk factors LPA was found to have a favorable $(++)$ association with waist circumference (WC) [eight [14, 23, 27, 29, 32, 35, 40, 45] of 12 studies (67\%)], triglycerides [eight $[14,24,25,27,31,32,37,40]$ of 11 studies $(73 \%)]$, insulin [five $[14,24,25,32,35]$ of six studies $(83 \%)$ ], and presence of metabolic syndrome [five [27, $32,35,40,45]$ of seven studies (67\%)], whereas an inconsistent (??) association with BMI [four [23, 29, 35, 45] of 10 studies (40\%)], and high density lipoprotein cholesterol (HDL-C) [four [21, 32, 40, 45] of 11 studies (36\%)] was observed. There was no (00) association with systolic blood pressure (SBP) [one of six [14, 24, 25, 32, 42, 45] studies (16\%)], diastolic blood pressure (DBP) [zero of four $[14,24,42,45]$ studies (0\%)], high blood pressure (BP) [one of five $[25,27,32,40,45]$ studies $(20 \%)]$, and glucose [only two [14, 15] of 11 studies $(18 \%)]$.

Evidence of the association with other cardiometabolic risk factors, such as fat mass, low density lipoprotein cholesterol (LDL-C), dyslipidemia, glycated hemoglobin, homeostasis model assessment (HOMA) $\beta$, HOMA R, C-reactive protein (CRP), lipid accumulation, and Framingham risk score were insufficient to determine the direction of association.

Mental health and cognitive function One cross-sectional study reported that LPA was associated with a low risk of psychological distress [38]. Two studies on older adults analyzed the association between LPA and cognitive function; one study indicated that LPA was significantly associated with higher cognitive functioning [33] whereas the other study found no associations between LPA and spatial working memory and task-switching [41].
Other outcomes Regarding the other health outcomes, there were two studies reporting favorable associations between LPA and the medical multimorbidity index [26, 29]. In addition, Loprinzi et al. found a favorable association between LPA and prostate-specific antigen concentrations [28].

\section{Longitudinal studies}

Mortality Four cohort studies investigated the association between LPA and mortality [13, 30, 36, 46], and all studies reported a significant decrease in mortality risk. Matthews et al. [36] reported that those who performed $4 \mathrm{~h}$ /day of LPA had a $21 \%$ lower risk of mortality compared with those who did less LPA ( $3 \mathrm{~h} /$ day). Three studies (Fishman et al. [30], Matthews et al. [36], and Schmid et al. [46]) indicated that replacing sedentary time with LPA was associated with a lower risk of mortality; replacing $30 \mathrm{~min}$ of sedentary time with LPA was associated with a $20 \%$ reduction in mortality risk [30], replacing $60 \mathrm{~min}$ of sedentary time with LPA was associated with a lower hazard of death in the low-activity groups but not in the high-activity groups [36], and a 30 min increase in LPA concurrent with an equal decrease in sedentary time reduced mortality risk in both age groups $(<65$ years and $\geq 65$ years), respectively. The study by Borgundvaag et al. [13] analyzed the combined effects of LPA and MVPA and showed that modest to high LPA was associated with a significantly lower death rate than low LPA when MVPA was low in women.

Cardiometabolic risk factors One cohort study for middle-aged Canadian adults reported that women in the highest tertiles of time performing LPA had lower fat mass, percent body fat, and central fat mass at 1 year follow-up, compared with women in the lowest and middle tertiles [44]. No significant effects were found in fat-free mass, peripheral fat mass, body weight, BMI, and WC [44].

Well-being One cohort study for older adults in Taiwan showed that LPA was associated with three dimensions of well-being: psychological, learning and growth, and social well-being [22].

\section{Duration of light-intensity physical activity bouts and health outcomes}

Three studies [27, 28, 35] analyzed whether performing LPA in bouts of different length differently associated with health outcomes. Robson et al. [27] indicated that for every $30 \mathrm{~min} /$ day of activity, there was a significant $4 \%$ reduction in the relative odds of having metabolic syndrome for bouted (lasting at least $10 \mathrm{~min}$ ) LPA, but not for sporadic (1-9 min) LPA. Bouted LPA was also associated with WC and triglyceride levels whereas 
Table 2 Summary of studies analyzing associations of objectively measured light-intensity physical activity with health outcomes after adjustment for moderate-to-vigorous physical activity in adults

\begin{tabular}{lll}
\hline & \multicolumn{2}{l}{ Summary of all included studies } \\
\cline { 2 - 3 } Mortality & Association \\
\hline Cardiometabolic risk factors & $4 / 4(100 \%)$ & Favorable (++) \\
WC & & \\
Obese/ adiposity/ BMI & $4 / 12(67 \%)$ & Favorable (++) \\
Fat mass/ percent body fat & $3 / 3(100 \%)$ & Favorable (+) \\
SBP & $1 / 6(17 \%)$ & No association (00) \\
DBP & $0 / 4(0 \%)$ & No association (00) \\
High BP & $1 / 5(20 \%)$ & No association (00) \\
HDL-C & $4 / 11(36 \%)$ & Inconsistent (??) \\
LDL -C & $0 / 3(0 \%)$ & No association (0) \\
Triglycerides & $8 / 11(73 \%)$ & Favorable (++) \\
Dyslipidemia & $0 / 1(0 \%)$ & No association (0) \\
Glucose & $2 / 11(18 \%)$ & No association (00) \\
Glycated hemoglobin & $0 / 2(0 \%)$ & No association (0) \\
Insulin/ diabetes & $5 / 6(83 \%)$ & Favorable (++) \\
HOMA $\beta$ & $1 / 2(50 \%)$ & Inconsistent (?) \\
HOMA R & $3 / 6(50 \%)$ & Inconsistent (?) \\
CRP & $1 / 4(25 \%)$ & No association (0) \\
Metabolic syndrome & $5 / 7(71 \%)$ & Favorable (++) \\
Lipid accumulation & $1 / 2(50 \%)$ & Inconsistent (?) \\
Framingham risk score & $0 / 1(0 \%)$ & No association (0) \\
Ment & &
\end{tabular}

Mental health and cognitive function

$\begin{array}{lll}\text { Mental health } & 1 / 1(100 \%) & \text { Favorable (+) } \\ \text { Well-being } & 1 / 1(100 \%) & \text { Favorable (+) } \\ \text { Cognitive health } & 1 / 2(50 \%) & \text { Inconsistent (?) }\end{array}$

Other outcomes

\begin{tabular}{lll} 
Medical multimorbidity & $2 / 2(100 \%)$ & Favorable $(+)$ \\
Prostate-specific antigen & $1 / 1(100 \%)$ & Favorable $(+)$ \\
\hline
\end{tabular}

No association (0): $0 \%-33 \%$ of the papers reported a statistically significant difference between LPA and outcomes, Indeterminate (?): $34-59 \%$ of the papers indicated a statistically significant difference, and favorable association $(+) /$ unfavorable association (-): $60 \%-100 \%$ of the papers showed a statistically significant favorable / unfavorable difference, respectively. When more than four studies supported an association or no association, it was coded as " 00 ", "++", or "--". "??" indicates inconsistent findings

$B M I$ Body mass index, $B P$ Blood pressure, $D B P$ Diastolic blood pressure, SBP Systolic blood pressure, WC Waist circumference, HDL-C High density lipoprotein cholesterol, LDL-C Low density lipoprotein cholesterol, HOMA Homeostasis model assessment, CRP C-reactive protein

$\mathrm{N}$ indicates the number of studies included in the review. $\mathrm{n}$ indicates the number of studies showing a favorable association

sporadic LPA was not. On the other hand, Jefferis et al. [35] reported BMI, WC, fat mass index, and insulin as factors benefitting from sporadic LPA in older men. Another study by Loprinzi et al. [28] found that every 1-h increment of activity, there was a significant $18 \%$ reduction in the odds ratio of having elevated prostate-specific antigen concentration for 1-min bout of LPA, but not for $\geq 10$-min bouts of LPA.

\section{Intensity of light-intensity physical activity and health outcomes}

One study [14] analyzed whether different light-intensity categories were associated with different cardiometabolic biomarkers. In the study by Howard et al. [14], both LLPA and HLPA were favorably associated with CRP, triglyceride levels, insulin, HOMA $\beta$, and HOMA R; and only LLPA showed significant favorable associations with WC. No association was observed in BMI, SBP, DBP, HDL-C, LDL-C, plasma glucose, and 2-h glucose.

\section{Sex differences in associations between light-intensity physical activity and health outcomes}

Three papers included in this review performed stratified analyses [13] or analyzed the interaction [14, 15] of sex differences in the effects of LPA on health outcomes. Borgundvaag et al. [13] found that a modest to high level of LPA was associated with a reduced mortality risk in women but not in men. In the study by Howard et al. [14], a significant interaction was observed by sex; association of HLPA with SBP tended to be beneficial in women only. On the other hand, Healy et al. [15] showed there was no sex interaction observed for the association between LPA and 2-h plasma glucose.

\section{Discussion}

To the best of our knowledge, this is the first systematic review of epidemiological studies analyzing associations of objectively measured LPA with various health outcomes after adjustment for MVPA in adults and older adults. Our present systematic review shows that objectively measured LPA was inversely associated with all-cause mortality risk and was favorably associated with some cardiometabolic risk factors, including WC, triglyceride levels, insulin, and the presence of metabolic syndrome. Associations of LPA with BMI and HDL-C were inconsistent. On the other hand, there was no association with $\mathrm{BP}$ and glucose levels.

There is accumulating evidence regarding the health benefits of LPA, but further research is still needed. Approximately $90 \%$ of the studies included in our present review targeted the Western population, and thus the generalization of our findings to other populations should be performed with caution. Further studies on various populations should be carried out in the future. Furthermore, most of the studies were cross-sectional, and therefore more longitudinal research should be required to establish causality between LPA and health outcomes. Because only a small number of studies stratified the participants by age and sex, it was difficult to make any conclusions regarding the effects of age and 
sex. With increasing age, PA patterns change [47-49]; LPA would play a more important role in determining overall PA in the older adult population than in the adult population. Regarding sex, few studies performed stratified analyses or analyzed interactions to observe sex differences in the effects of LPA on health outcomes. Considering sex differences in metabolism (e.g., fat metabolism) and the fact that a number of previous studies using objective measurements reported that women engaged in more LPA than men $[3,15,50]$, sex-stratified data are also warranted in future research.

The effects of LPA may depend on health outcomes. In the current review, LPA appears to be associated with some metabolic factors, including WC, triglyceride levels, insulin, BMI, and HDL-C, but not with BP. The physiological mechanisms underlying the observed associations are speculative. However, all factors associated with LPA are relevant to metabolic syndrome/diabetes followed by fat accumulation [51]. The increased activity of lipoprotein lipase and hormone-sensitive lipase that regulates lipid metabolism following muscular contractions causes decomposition of triglycerides into free fatty acid (FFA) [52-54], which reduces the triglycerides from the circulation. FFA is the primary fuel during low intensity activity [55]. Increased energy expenditure by LPA may be the reason for these the associations of LPA with fat-related metabolism. It is estimated that $1 \mathrm{~h}$ per day shift from SB to LPA (additional one MET-hour) would increase energy expenditure by about $3 \%$, which could be significant to receive health benefits $[25,36]$. On the other hand, LPA appears not to be associated with BP. Higher intensity PA may be needed for favorable effects on BP [56].

\section{Limitations}

Several limitations should be considered when interpreting our present findings. First, this review used the P-counting method to summarize the research findings. It was not possible to perform a meta-analysis since there were some discrepancies and inconsistencies in how LPA was defined and analyzed between studies and populations. Analyzing accelerometer data using standardized methods will be helpful towards improving the quality of the scientific literature on PA and for maximizing comparability and synthesizing the results. Second, we cannot deny the effects of the differences in confounding adjustments that affect the associations between LPA and health outcomes. Third, our search strategy was restricted to studies written in English or Japanese, which might have resulted in language bias. Fourth, all of the studies included except one study [24] use a non-compositional approach. Therefore, the co-dependence of time-use domains is not totally taken into account. Further studies are needed to investigate combined effects of time spent in PA, SB and sleep on health markers using a compositional data analysis. Finally, there were no intervention studies and most of the studies were cross-sectional, which does not enable us to address the direction of causality. Therefore, additional longitudinal or intervention studies are needed to confirm these findings reported in this review. In the future, LPA should be measured and reported when intervention studies are performed, even on other time-use domains.

\section{Conclusions}

This review highlights previous studies on the associations of objectively measured LPA and important health outcomes in adults. After adjustment for MVPA, LPA was inversely associated with all-cause mortality risk and was favorably associated with some cardiometabolic risk factors including WC, triglyceride levels, insulin, and the presence of metabolic syndrome. Although current global PA guidelines recommend only MVPA, promoting LPA may confer additional health benefits. Therefore, the inclusion of LPA in the PA recommendations should be considered in the future.

\section{Additional file}

\section{Additional file 1: Search Terms. (DOCX $27 \mathrm{~kb})$}

\section{Abbreviations}

BMI: Body mass index; BP: Blood pressure; CPM: Counts per minute; CRP: Creactive protein; DBP: Diastolic blood pressure; HDL-C: High density lipoprotein cholesterol; HLPA: High light-intensity physical activity; HOMA: Homeostasis model assessment; LDL-C: Low density lipoprotein cholesterol; LLPA: Low light-intensity physical activity; LPA: Light-intensity physical activity; METs: Metabolic equivalents; MVPA: Moderate-to-vigorous physical activity; PA: Physical activity; SB: Sedentary behavior; SBP: Systolic blood pressure; WC: Waist circumference

\section{Funding}

This study was supported by a Grant-in-Aid for Scientific Research from the Japan Ministry of Education, Culture, Sports, Science and Technology (16H03249), and MEXT-Supported Program for the Strategic Research Foundation at Private Universities, 2015-2019 from the Ministry of Education, Culture, Sports, Science and Technology (S1511017).

Availability of data and materials

Authors can confirm that all relevant data are included in the article.

\section{Authors' contributions}

SA and MM performed data extraction. SA prepared the manuscript draft. $M M, N F, H K, T, Y O$, and SI interpreted the results, revised the manuscript drafts, and provided critical comments during the process. All authors read and approved the final version of the manuscript.

\section{Ethics approval and consent to participate}

Not applicable.

\section{Consent for publication}

Not applicable.

\section{Competing interests}

The authors declare that they have no competing interests. 


\section{Publisher's Note}

Springer Nature remains neutral with regard to jurisdictional claims in published maps and institutional affiliations.

Received: 6 February 2018 Accepted: 21 June 2018

Published online: 09 July 2018

\section{References}

1. Lee IM, Shiroma EJ, Lobelo F, Puska P, Blair SN, Katzmarzyk PT. Effect of physical inactivity on major non-communicable diseases worldwide: an analysis of burden of disease and life expectancy. Lancet. 2012;380:219-29.

2. World Health Organization (WHO): Global recommendations on physical activity for health. http://apps.who.int/iris/bitstream/10665/44399/1/ 9789241599979_eng.pdf. Accessed 11 Dec 2017.

3. Amagasa S, Fukushima N, Kikuchi H, Takamiya T, Oka K, Inoue S. Light and sporadic physical activity overlooked by current guidelines makes older women more active than older men. Int J Behav Nutr Phys Act. 2017;14:59.

4. Donahoo WT, Levine JA, Melanson EL. Variability in energy expenditure and its components. Curr Opin Clin Nutr Metab Care. 2004;7:599-605.

5. Espinel PT, Chau JY, van der Ploeg HP, Merom D. Older adults' time in sedentary, light and moderate intensity activities and correlates: application of Australian time use survey. J Sci Med Sport. 2015;18:161-6.

6. Young DR, Hivert MF, Alhassan S, Camhi SM, Ferguson JF, Katzmarzyk PT, Lewis CE, Owen N, Perry CK, Siddique J, Yong CM. Sedentary behavior and cardiovascular morbidity and mortality: a science advisory from the American Heart Association. Circulation. 2016:134:e262-79.

7. Dunstan DW, Howard B, Healy GN, Owen N. Too much sitting-a health hazard. Diabetes Res Clin Pract. 2012;97:368-76.

8. Lee IM, Shiroma EJ. Using accelerometers to measure physical activity in large-scale epidemiological studies: issues and challenges. Br J Sports Med. 2014;48:197-201.

9. Shephard RJ, Tudor-Locke C. The objective monitoring of physical activity: contributions of Accelerometry to epidemiology, exercise science and rehabilitation. 1st ed: Springer International Publishing; 2016. https://www. springer.com/us/book/9783319295756.

10. Autenrieth CS, Baumert J, Baumeister SE, Fischer B, Peters A, Doring A, Thorand B. Association between domains of physical activity and all-cause, cardiovascular and cancer mortality. Eur J Epidemiol. 2011;26:91-9.

11. Huerta JM, Chirlaque MD, Tormo MJ, Buckland G, Ardanaz E, Arriola L, Gavrila D, Salmeron D, Cirera L, Carpe B, et al. Work, household, and leisuretime physical activity and risk of mortality in the EPIC-Spain cohort. Prev Med. 2016;85:106-12.

12. Jefferis BJ, Sartini C, Ash S, Lennon LT, Wannamethee SG, Whincup PH. Validity of questionnaire-based assessment of sedentary behaviour and physical activity in a population-based cohort of older men; comparisons with objectively measured physical activity data. Int J Behav Nutr Phys Act. 2016;13:14.

13. Borgundvaag $E$, Janssen I. Objectively measured physical activity and mortality risk among American adults. Am J Prev Med. 2017;52:e25-31.

14. Howard B, Winkler EA, Sethi P, Carson V, Ridgers ND, Salmon JO, Healy GN, Owen N, Dunstan DW. Associations of low- and high-intensity light activity with Cardiometabolic biomarkers. Med Sci Sports Exerc. 2015;47: 2093-101.

15. Healy GN, Dunstan DW, Salmon J, Cerin E, Shaw JE, Zimmet PZ, Owen N. Objectively measured light-intensity physical activity is independently associated with 2-h plasma glucose. Diabetes Care. 2007;30:1384-9.

16. Fuzeki $E$, Engeroff $T$, Banzer W. Health benefits of light-intensity physical activity: a systematic review of accelerometer data of the National Health and nutrition examination survey (NHANES). Sports Med. 2017;47:1769-93.

17. Moher D, Liberati A, Tetzlaff J, Altman DG. Preferred reporting items for systematic reviews and meta-analyses: the PRISMA statement. J Clin Epidemiol. 2009;62:1006-12.

18. Batacan RB Jr, Duncan MJ, Dalbo VJ, Tucker PS, Fenning AS. Effects of light intensity activity on CVD risk factors: a systematic review of intervention studies. Biomed Res Int. 2015;2015:596367.

19. Sallis JF, Prochaska JJ, Taylor WC. A review of correlates of physical activity of children and adolescents. Med Sci Sports Exerc. 2000;32:963-75.

20. Hawkins MS, Gabriel KP, Conroy MB, Cooper J, Sutton-Tyrrell K. Physical activity intensity and cardiovascular risk by ankle-brachial index. Vasc Med. 2013;18:79-84.
21. Alkahtani S, Elkilany A, Alhariri M. Association between sedentary and physical activity patterns and risk factors of metabolic syndrome in Saudi men: a cross-sectional study. BMC Public Health. 2015;15:1234.

22. Ku PW, Fox KR, Liao Y, Sun WJ, Chen LJ. Prospective associations of objectively assessed physical activity at different intensities with subjective well-being in older adults. Qual Life Res. 2016;25:2909-19.

23. Lynch BM, Friedenreich CM, Winkler EA, Healy GN, Vallance JK, Eakin EG, Owen N. Associations of objectively assessed physical activity and sedentary time with biomarkers of breast cancer risk in postmenopausal women: findings from NHANES (2003-2006). Breast Cancer Res Treat. 2011;130:183-94.

24. Chastin SF, Palarea-Albaladejo J, Dontje ML, Skelton DA. Combined effects of time spent in physical activity, sedentary behaviors and sleep on obesity and cardio-metabolic health markers: a novel compositional data analysis approach. PLoS One. 2015;10:e0139984.

25. Buman MP, Winkler EA, Kurka JM, Hekler EB, Baldwin CM, Owen N, Ainsworth BE, Healy GN, Gardiner PA. Reallocating time to sleep, sedentary behaviors, or active behaviors: associations with cardiovascular disease risk biomarkers, NHANES 2005-2006. Am J Epidemiol. 2014;179:323-34.

26. Loprinzi PD. Light-intensity physical activity and medical multimorbidity. South Med J. 2016;109:174-7.

27. Robson J, Janssen I. Intensity of bouted and sporadic physical activity and the metabolic syndrome in adults. PeerJ. 2015;3:e1437.

28. Loprinzi PD, Kohli M. Effect of physical activity and sedentary behavior on serum prostate-specific antigen concentrations: results from the National Health and nutrition examination survey (NHANES), 2003-2006. Mayo Clin Proc. 2013;88:11-21.

29. Loprinzi PD, Sheffield J, Tyo BM, Fittipaldi-Wert J. Accelerometer-determined physical activity, mobility disability, and health. Disabil Health J. 2014;7:419-25.

30. Fishman El, Steeves JA, Zipunnikov V, Koster A, Berrigan D, Harris TA, Murphy R. Association between objectively measured physical activity and mortality in NHANES. Med Sci Sports Exerc. 2016;48:1303-11.

31. Green AN, McGrath R, Martinez V, Taylor K, Paul DR, Vella CA. Associations of objectively measured sedentary behavior, light activity, and markers of cardiometabolic health in young women. Eur J Appl Physiol. 2014;114:907-19.

32. Camhi SM, Sisson SB, Johnson WD, Katzmarzyk PT, Tudor-Locke C. Accelerometer-determined moderate intensity lifestyle activity and cardiometabolic health. Prev Med. 2011;52:358-60.

33. Johnson LG, Butson ML, Polman RC, Raj IS, Borkoles E, Scott D, Aitken D, Jones $\mathrm{G}$. Light physical activity is positively associated with cognitive performance in older community dwelling adults. J Sci Med Sport. 2016; 19(11):877-82.

34. Foong YC, Aitken D, Winzenberg T, Otahal P, Scott D, Jones G. The association between physical activity and reduced body fat lessens with age - results from a cross-sectional study in community-dwelling older adults. Exp Gerontol. 2014;55:107-12.

35. Jefferis BJ, Parsons TJ, Sartini C, Ash S, Lennon LT, Wannamethee SG, Lee IM Whincup PH. Does duration of physical activity bouts matter for adiposity and metabolic syndrome? A cross-sectional study of older British men. Int J Behav Nutr Phys Act. 2016:13:36.

36. Matthews CE, Keadle SK, Troiano RP, Kahle L, Koster A, Brychta R, Van Domelen D, Caserotti P, Chen KY, Harris TB, Berrigan D. Accelerometermeasured dose-response for physical activity, sedentary time, and mortality in US adults. Am J Clin Nutr. 2016;104:1424-32.

37. Hamer M, Stamatakis E, Steptoe A. Effects of substituting sedentary time with physical activity on metabolic risk. Med Sci Sports Exerc. 2014;46:1946-50.

38. Hamer M, Coombs N, Stamatakis E. Associations between objectively assessed and self-reported sedentary time with mental health in adults: an analysis of data from the health survey for England. BMJ Open. 2014;4:e004580.

39. Nelson RK, Horowitz JF, Holleman RG, Swartz AM, Strath SJ, Kriska AM, Richardson CR. Daily physical activity predicts degree of insulin resistance: a cross-sectional observational study using the 2003-2004 National Health and nutrition examination survey. Int J Behav Nutr Phys Act. 2013;10:10.

40. Ekblom-Bak E, Ekblom O, Bergstrom G, Borjesson M. Isotemporal substitution of sedentary time by physical activity of different intensities and bout lengths, and its associations with metabolic risk. Eur J Prev Cardiol. 2016;23:967-74.

41. Fanning J, Porter G, Awick EA, Ehlers DK, Roberts SA, Cooke G, Burzynska AZ, Voss MW, Kramer AF, McAuley E. Replacing sedentary time with sleep, light, or moderate-to-vigorous physical activity: effects on self-regulation and executive functioning. J Behav Med. 2016;40:332-42. 
42. Scheers T, Philippaerts R, Lefevre J. SenseWear-determined physical activity and sedentary behavior and metabolic syndrome. Med Sci Sports Exerc. 2013;45:481-9.

43. Salonen MK, Wasenius N, Kajantie E, Lano A, Lahti J, Heinonen K, Raikkonen K, Eriksson JG. Physical activity, body composition and metabolic syndrome in young adults. PLoS One. 2015;10:e0126737.

44. Riou ME, Abdulnour J, Brochu M, Prud'homme D, Rabasa-Lhoret R, Doucet E. Light physical activity is a better determinant of lower adiposity during the menopausal transition. Climacteric. 2014;17:79-86.

45. Kim J, Tanabe K, Yokoyama N, Zempo H, Kuno S. Objectively measured light-intensity lifestyle activity and sedentary time are independently associated with metabolic syndrome: a cross-sectional study of Japanese adults. Int J Behav Nutr Phys Act. 2013;10:30.

46. Schmid D, Ricci C, Baumeister SE, Leitzmann MF. Replacing sedentary time with physical activity in relation to mortality. Med Sci Sports Exerc. 2016;48:1312-9.

47. McPhee JS, French DP, Jackson D, Nazroo J, Pendleton N, Degens H. Physical activity in older age: perspectives for healthy ageing and frailty. Biogerontology. 2016;17:567-80.

48. Tanaka C, Fujiwara Y, Sakurai R, Fukaya T, Yasunaga M, Tanaka S. Locomotive and non-locomotive activities evaluated with a triaxial accelerometer in adults and elderly individuals. Aging Clin Exp Res. 2013;25:637-43.

49. Sparling PB, Howard BJ, Dunstan DW, Owen N. Recommendations for physical activity in older adults. BMJ. 2015;350:h100.

50. Berkemeyer K, Wijndaele K, White T, Cooper AJ, Luben R, Westgate K, Griffin SJ, Khaw KT, Wareham NJ, Brage S. The descriptive epidemiology of accelerometer-measured physical activity in older adults. Int J Behav Nutr Phys Act. 2016;13:2.

51. Armani A, Berry A, Cirulli F, Caprio M. Molecular mechanisms underlying metabolic syndrome: the expanding role of the adipocyte. FASEB J. 2017;31: 4240-55.

52. Eckel RH. Lipoprotein lipase. A multifunctional enzyme relevant to common metabolic diseases. N Engl J Med. 1989;320:1060-8.

53. Kantor MA, Cullinane EM, Herbert PN, Thompson PD. Acute increase in lipoprotein lipase following prolonged exercise. Metabolism. 1984;33:454-7.

54. Huttunen JK. Physical activity and plasma lipids and lipoproteins. Ann Clin Res. 1982;34:124-9.

55. Romijn JA, Coyle EF, Sidossis LS, Gastaldelli A, Horowitz JF, Endert E, Wolfe RR. Regulation of endogenous fat and carbohydrate metabolism in relation to exercise intensity and duration. Am J Physiol Endocrinol Metab. 1993;265:E380-91.

56. Cornelissen VA, Smart NA. Exercise training for blood pressure: a systematic review and meta-analysis. J Am Heart Assoc. 2013;2:e004473.

\section{Ready to submit your research? Choose BMC and benefit from:}

- fast, convenient online submission

- thorough peer review by experienced researchers in your field

- rapid publication on acceptance

- support for research data, including large and complex data types

- gold Open Access which fosters wider collaboration and increased citations

- maximum visibility for your research: over $100 \mathrm{M}$ website views per year

At BMC, research is always in progress.

Learn more biomedcentral.com/submissions 